\title{
HIV/AIDS in Physiotherapy Education - Mainstreaming Using UN Principles
}

\begin{abstract}
HIV /AIDS remains at epidemic levels in South Africa with one in ten people affected by the HI virus. The United Nations program for AIDS (UNAIDS) has defined five principles that can be used to mainstream HIV. The five key principles are: the development of a clearly defined entry point; use of existing policies, structures and frameworks; advocacy sensitization and capacity building; distinguishing between the external (institutional interventions) and internal (staff risks and vulnerability) domain; and developing strategic partnerships. A proposed HIV curriculum for physiotherapists was been developed from a series of studies undertaken to understand the issues related to HIV using the principles of mainstreaming.

The purpose of this paper is to explore how each principle of mainstreaming can be applied in physiotherapy education and curricula.

Each mainstreaming principle was considered and ways in which it could be mainstreamed into physiotherapy training and practice, using data from the patients', academics' and clinicians' experience were proposed.

The five principles can be used in South African settings. In principle one the aetiology, approaches to treatment, management of conditions and symptoms are used to identify entry points for introducing HIV teaching. Relevant examples of conditions associated with HIV include pain, stroke, specific muscle weakness patterns, fatigue and cardiopulmonary system problems (e.g. breathlessness). The role of physiotherapy in HIV management is also a good entry point.

For principle two, policies were considered. Pertinent areas such as antiretroviral use, frameworks such as the International Classification of Function (ICF), Worthington's rehabilitation framework and CBR can also be integrated with HIV physiotherapy curriculum and practice. Sensitised and aware staff as promoted in principle three, can advocate for affected patients and role model appropriate practice and attitudes in HIV management thus contributing to reducing stigma and burnout. Integrating policies with the need to avoid risks and correct inappropriate attitudes of staff is promoted and promoting strategic partnerships and collaborative work will help provide appropriate services.

Using the mainstreaming principles allows for the inclusion of HIV content in physiotherapy education and practice. Both physiotherapy curriculum and continuous professional development may use this information to respond appropriately.
\end{abstract}

KEY WORDS: HIV/AIDS, EDUCATION, MAINSTREAMING, PHYSIOTHERAPY.

\section{INTRODUCTION}

Human immune deficiency virus (HIV) is a vast and complex subject with many implications for physiotherapy education and practice. This paper attempts to assess the inclusion of HIV/AIDS into a physiotherapy curriculum and practice according to the United Nations defined mainstreaming criteria. The results of four studies Myezwa et al., 2009, Myezwa 2008, Van As 2009, Myezwa et al., 2005 are utilised and discussed to illustrate how they affect the South African physiotherapy curriculum.

The rationale for using this approach can be found in Verbrugenn's (2004)'s outline of mainstreaming HIV. One of the main advantages of mainstreaming HIV is that it brings the issue to the fore and into the core business agenda, so that it becomes part and parcel of a programme. Similarly, in education, Hunt et al. (1998) refer to mainstreaming as a method of taking a key goal of a learning area from the periphery and placing it into the centre and within the entire curriculum. Hunt (1998) acknowledges mainstreaming within the curriculum at subject level as an effective means of incorporating an important topic into the curriculum. The focus of this paper is thus on mainstream- ing HIV/AIDS into the physiotherapy curriculum and the discussion is structured around the key principles of this process which according to the UNAIDS (2002) are:

\section{Corresponding Author:}

Hellen Myezwa

University Of Witwatersrand

7 York Road

Park Town 2093

Johannesburg

E-mail: Hellen.Myezwa@wits.ac.za 
1. The development of a clearly defined entry point for mainstreaming HIV/ AIDS

2. Mainstreaming should take place within existing policies and frameworks and should be located within existing institutional structures.

3. Advocacy, sensitisation and capacity building to place health workers in a better position to undertake mainstreaming should take place.

4. A distinction between the external and internal domains must be made. Internal domains includes risks and vulnerability and the external domains include issues such as an institution undertaking interventions based on its mandate and capacity in support of national and local strategic efforts

5. Developing strategic partnerships based on comparative advantage, cost effectiveness and collaboration

Using the results of the four studies, outlined below as well as an extensive literature review mainstreaming principles were applied.

The first study established referral patterns of patients with HIV to physiotherapy. This study contributed to understanding the different conditions present in patients with HIV and which ones are suitable for physiotherapy (Myezwa et al., 2005). Furthermore, the results showed how many patients affected were referred for physiotherapy.

The second study involved 80 inpatients and 51 out-patients living with HIV and outlined their impairments, activity limitations and participation restrictions (Myezwa et al., 2009).

The third study explored a focus group discussion (FGD) on clinicians' and academics' perceptions and experiences with HIV to enrich the picture of what topics should concern physiotherapists (Myezwa 2008).

A fourth study used a Delphi technique to test consensus on curriculum content among academic staff at all eight universities that offer physiotherapy training in South Africa (Myezwa et al., in press).

\section{APPLYING MAINSTREAMING PRINCIPLES}

The paper provides how, within the teaching of physiotherapy, the five principles can be integrated using findings from the four studies by Myezwa et al., (2005, 2008, 2009 and in press). The same results from each study may apply to more than one principle, although the application may be different. An audit of all eight physiotherapy curricula to determine the extent of HIV inclusion revealed that the majority of physiotherapy curricula did not comprehensively include HIV (Myezwa 2008) Most of the relevant content was loosely woven into the curriculum and arbitrarily dependent on the interest of the lecturer.

\section{Principle 1: A clearly defined entry point for mainstreaming HIV/AIDS}

The entry point is seen as a position in the core business, at which one can start to include the matter to be mainstreamed. In this case, the physiotherapy curriculum and practice is the core business. The generic curriculum, that teaches basic aetiology, pathophysiology and a largely biopsychosocial approach to patient management presents a ready opportunity for mainstreaming management of HIV/AIDS.

An extensive literature review on HIV/AIDS was conducted as part of the process of collating information important for the development of a curriculum on HIV and placing it into a rehabilitation framework such as the International Classification of Function (ICF) (Myezwa 2008). The review includes explanations of the genesis of the disease, principal modes of transmission, evaluation of drug trials and other forms of treatment potentially used to slow down the degenerative process associated with HIV disease (Azzam 2006, Volberding et al 2003, Evans and Scadden 2000). Other topics were HIV virology and subsequent staging and antiretroviral therapy. These topics were found to be fundamental in the training of all health workers, including the physiotherapist (Myezwa et al in press; Flaskrud \& Ungvarski, 1999). Thus the current basic sciences are an already used entry point at which HIV can be included and should be reviewed to ensure they correspond with what is required by physiotherapists.

Reports in the literature have explored the effect of HIV on body systems. The impairment and subsequent impact on the patients' activity levels and quality of life was also ascertained (Myezwa et al., 2009, Rusch et al., 2004). Common systems, that are considered pertinent to physiotherapy practice, and are affected by HIV are cardiopulmonary (Diaz 1999), haematological (Evans \& Scadden, 2000; Mars, 2004), metabolic (Mutimura et al., 2008a,c), neurological (Ricardo-Dukelow et al., 2007, Cherner et al., 2002) and musculoskeletal systems (Sattler et al., 1999; Sattler et al., 2002). Experiences of clinicians and academics emphasise the need to include HIV effects into the teaching of the different body systems. The management of each of these systems is already taught and commonly seen in the clinical setting. The specific effects of HIV on multiple systems are important in teaching and clinical reasoning. For example, HIV directly affects either progenitor cells or indirectly through opportunistic infections, it can produce symptoms that are from multiple aetiologies, thus impacting on clinical reasoning. Similarly is: dyspnoea may be as a result of the direct effects on the haematological system or the pathological effects of opportunistic and recurrent infections, like pneumocystic jiroveci pneumonia on oxygen exchange. Thus by implication, these differences in causes and their effects on treatment should be addressed during training by the respective area of speciality. Similarly, impairments such as pain, fatigue and loss of body mass commonly occur in HIV. Physiotherapy curricula include the basic structure, function and relevant pathogenesis of systems related to these impairments (CSP, 2008b) and therefore entry points for teaching on how HIV impacts on these systems can be identified. The emergence of HIV, however has affected the aetiology and morbidity of all the conditions traditionally treated and this is further complicated by problems of stigma, fear and the need for a very strong health and inter-sectoral support system. A decision thus would need to be made, as to how much content on HIV/AIDS should be included in undergraduate or post graduate education.

Recent graduates and academics (Myezwa 2008) felt that the way HIV 
was included in the existing curricula was problematic and further analysis indicated that institutions had not looked comprehensively at the issues of HIV content, mode of delivery and integration of HIV-related aspects in the general curriculum.

The impacts of HIV on the socio-economic and socio-cultural environment of the patient should also be considered. The impact on the body systems results in a wide range of impairments, activity limitation and disability. Myezwa et al (2009), Van As et al., (2009); Zonta et al., (2003) ; Zonta et al., (2005) revealed clear patient profiles. Understanding the particular patient profiles allows the practitioner and the academic to give better guidance on the assessment of people with HIV or AIDS and to integrate relevant HIV knowledge attitudes and skills. One line of thought is that people with HIV/AIDS already experience similar problems to other patient groups seen by physiotherapists and therefore skills and knowledge should be transferable and tapped. It is a valid argument that physiotherapists have the fundamental knowledge and skills to assess and treat patients, however further research is necessary to establish if this assumption is true. In some cases there maybe information that is particular to the HIV infected patient that may need to have attention. An example of this is the reduced proximal muscle power seen in different patient groups (Myezwa et al., 2009) therefore specific assessment focus should be included in the curriculum. Another example is why on an activity and participation level patients reported no community integration. They attributed this restriction to fear of not being able to find a toilet quickly enough thus had self-imposed restriction in movement and participation in community activity (Myezwa et al., 2009).

Another entry point for mainstreaming education about HIV could be during teaching on rehabilitation and physiotherapy interventions, including maintaining or increasing the level of physical activity and exercise. Exercise, in particular, as part of behaviour modification and change in life style, has been shown to provide a positive contribution to the prevention and care of HIV manifestations (Nixon et al., 2010, 2005; Rusch et al., 2004). Aerobic exercise primarily changes the mitochondrial and cytosolic proteins while resisted exercise increases muscle protein (Zinna \& Yarasheski, 2003). The effects of exercise on specific HIV conditions such as lipodystrophy (Mutimura et al., 2007) fatigue and body mass changes for example, were areas that experienced and newly qualified academic and clinical staff recommended input. Other interventions such as electrotherapy, use of aids and appliances massage are still being investigated for their effects on HIV/AIDS. These investigations have shown positive clinical effects, however, most studies are still challenged by small sample sizes, difficulties with blinding, standardisation and poor isolation of treatment, due to the nature of treating HIV. (Fulk et al., 2004; Galantino et al., 1999; Posner et al., 2004; ShorPosner et al., 2004; Worthington et al., 2005). Incorporation into teaching should therefore take cognisance of the levels of evidence.

In defining entry points, the challenge for the lecturer is to keep a balance in equipping the graduate with the necessary knowledge while avoiding continuous additions to the curriculum and balancing undergraduate time. In spite of this, much of the identified HIV content can be included in existing content and need not lead to additional lectures or more time, but adding to how HIV changes the clinical picture and in doing this, mainstream the content.

\section{Principle 2: Mainstreaming should take place within existing policies, philoso- phies and frameworks}

Policies and frameworks are assessed at two levels namely the macro and micro levels. In response to the call for national responses and incorporation of HIV into all programmes by UNAIDS, the government called for all sectors to respond by incorporating HIV into their core business (Department of Health, 2007b). All eight universities have HIV policies that guide the implementation of response to infection and inclusion in subject matter. For example, the University of the Witwatersrand policy states that all university undergraduates must be exposed to basic knowledge of HIV and its mode of transmission. Thereafter it would follow for all departments to identify specific areas within their courses where inclusion of HIV is pertinent.

The study exploring the perceptions of clinicians and academics categorised curricula concerns at macro, meso and micro levels (Myezwa 2008). Under macro level issues, participants supported the need to include HIV because of its high prevalence and thus a national priority. An understanding of the current policies and frameworks is important for physiotherapists and would help them in defining their role and making informed decisions. Only one of the seven universities, whose curricula were reviewed, reflected policies and frameworks (Myezwa 2008). Verbruggens (2004) proposes the use of frameworks to locate and contextualise the specific place for HIV in any area of work. For physiotherapists, Worthington's (2005) rehabilitation approach which underscores a multisectoral approach, and the ICF approach, (Anandan et al., 2006, Hwang \& Nochajski, 2003) can be used as they account for disability in different life domains. Using ICF would include individual needs in physical, functional, psychological, spiritual, social and vocational aspects. At the meso level participants expressed a fragmented and uncoordinated approach to HIV curricula input. This may be indicative of the lack of teaching around a framework that "pulls" the subject together.

It is relatively easy to apply the ICF as most studies show how HIV causes numerous impairments that impact on function or quality of life (Myezwa et al 2009, 2011, Van As et al 2009., Anandan et al., 2006; Vidrine et al., 2003; Zonta et al., 2005). Specific aspects of function and quality of life such as mobility, instrumental activities and self-care activities were illuminated in these studies. These are areas with which physiotherapy is concerned and therefore the ICF framework and Worthington's framework are appropriate to be applied to HIV. The ICF which is in the physiotherapy curriculum is considered as a generic approach that facilitates clinical reasoning through the continuum 
of problems i.e. impairment to environment. Related to the ICF and the bio-psychosocial approach are service delivery models such as CBR. CBR is an already well understood concept that is taught to physiotherapists. CBR principles allow the rehabilitation of a client within a community focussed paradigm (Helander,1994).

\section{Principle 3: Advocacy sensitisation and capacity Building}

Advocacy is a process of active support that involves acting as a liaison or canvassing for a particular cause to be considered (Jacobs \& Jacobs, 2004). Once HIV is recognised as requiring advocacy it is necessary to get support from the people who are instrumental in the implementation of intervention programmes. What sets HIV apart from other conditions is its pervasive nature, a high prevalence and the complexities it presents for the clinical situation. One clinician sums it up in this statement:

"I think it's so vast and that it actually connects with so many other conditions that we could integrate it. HIV is part of everything because HIV affects your pathology, your recovery, your rehab, whatever." (Clinician)

For physiotherapy, mainstreaming HIV into education and practice one needs the facts to use as advocacy tools. The proposed curriculum content framework developed from the results of all the studies by Myezwa et al (2005, 2008, and 2009 , in press) can be used as an advocacy tool.

Evidence suggests that problematic attitudes among health workers, as well as a lack of accurate information about HIV AIDS can make a significant negative impact on the health worker's approach to HIV. Capacity building and training can improve knowledge, skills and attitude increasing the level of comfort in dealing with those who are HIV infected (Kent et al., 2005). However, many clinicians expressed feeling illequipped and some academics and clinicians' showed a lack of knowledge as to how to manage HIV/AIDS (Myezwa 2008). The same study showed that most topics were viewed as inadequately taught or not taught at all. Reports on the curricula presented an ad-hoc and frag- mented inclusion of the subject, which was not dependent on current policies, prevalence clinicians' experiences, the number of patients or their clinical profile. Clinicians supported this interpretation, by stating that their own input on HIV, as students, had been somewhat fragmented and resulted in knowledge gaps. Students and qualified therapists should be equipped with the necessary skill to apply known principles of physiotherapy and rehabilitation to their treatment of HIV and they need an appropriate level of knowledge (Puckree et al., 2004; Puckree et al., 2002; Ukwakwe, 2000). Use of evaluation and selfdirected learning to extend their capacity and skills in managing HIV should be actively encouraged to augment their ability to manage HIV, with its ever changing profile (Hunt et al., 1998).

For example, the role of physiotherapy in HIV falls within the educational outcome of understanding of physiotherapeutic principles, philosophies and problem-solving with due consideration for disease processes. Working from what is known to the unknown is a known teaching and learning strategy (CSP, $2008 \mathrm{~b}$ ) and can it be used for sensitisation and capacity building ( Myezwa et al in press). For effective capacity building, gaps and omissions in the curriculum are a good starting and must be addressed for both the undergraduate and the qualified staff. To effect real change, advocacy is needed to ensure the required change to the curriculum.

Clinicians stated that their role in HIV management was unclear. No evidence of an outcome to increase the understanding of physiotherapeutic principles, philosophies and problem-solving with due consideration for the impact of HIV/ AIDS input was found (Myezwa 2008). Approaches to gaining a better understanding of the complexities of HIV management that are currently proposed include the use of problem-based learning, and inter-professional education. Other proposals include using people living with HIV/AIDS as facilitators of HIV education sessions and developing trans-disciplinary management models (Canadian Working Group on HIV and Rehabilitation, 2002b; Solomon et al., 2003b).
The role of the physiotherapist will be fluid and will change depending on whether they are in a hospital, outpatient or community setting, or if the patient is in a period of wellness or illness. The hospital setting may call predominantly for their clinical skills and working within a multi-disciplinary team. For example, therapists may need to respond to acute problems such as neurological, respiratory or neuromuscular problems with co-morbidities. Palliative approaches may also be required (Uwimana \& Louw, 2007). In an out-patient setting, the therapist may be required, to use a wellness approach that needs the patient with HIV to focus on managing their risks and maintaining their health (O'Brien et al., 2007). Many of the skills required to fulfil these roles are already known to physiotherapists and they need to access them in an HIV context.

Clinicians reported feeling overwhelmed by the number of patients, their inability to define what their role is, and their limited background knowledge of specific HIV related conditions. The presence of co-morbities in the patients seen and clinicians' inability to deal with them was seen as problematic. In addition to building capacity that concerns clinical practice and teaching, HIV is a condition fraught with major complications that influence the individual. Issues of stigma, disclosure and fear have been documented as almost paralysing health workers into inaction (Vance \& Denham, 2008). This may underscore the need to build capacity among physiotherapists and deal with $\mathrm{HIV}$ in an inter-professional manner as the presenting problems are multifactorial.

\section{Principle 4: The distinction between the internal and external domains}

The internal domains refer to staff risks and vulnerability. The external domains refer to the institutional efforts in support of national, local and strategic efforts. Some results point to issues that threaten management and mainstreaming of HIV. In terms of the external domain, academic and clinical staff are aware of the need to include HIV as there are national calls to do so (Department of Education, 
1999; Department of Health, 2007b;). In addition, the inclusion and integration of HIV is required in response to the increased prevalence and changing clinical picture. In Myezwa's study (2008), academics and clinicians, in theory embraced the policies and theories guiding input in relation to HIV, but did not appear to put these into practice.

With regard to the internal domain, many staff anxieties emerged from the focus group discussions that included their knowledge gaps and inappropriate attitudes and perceptions (Myezwa 2008). Meeting knowledge gaps and addressing attitude problems in both undergraduate and qualified staff may impact on clinical decision-making and educational input. The impact on such fundamental educational activities may present a risk that HIV/AIDS will not be included appropriately into both education and practice. Another aspect that clinicians reported as having a direct impact on their ability to assimilate and apply knowledge on HIV, was the lecturers' attitudes and beliefs. Clinicians reported how the demeanour of the lecturer affected their impressions of HIV. Clinicians emphasised the need for a positive and informed outlook in managing HIV/AIDS, in particular, avoiding behaviours such as, treating the condition and not the person, being judgemental and viewing HIV, as a death sentence. This perception, on the part of students, supports Eisner's (1992) notion that the impact of the implicit and null curriculum does influence what students learn. They recommended that important changes that help engender a positive outlook to the management of HIV/AIDS were that the prognosis has changed with the advent of ARVs and that opportunistic infections can be managed. Loss of hope, loss of morale, and patient overload affected therapists on a personal level. These responses are in no way peculiar to qualified therapists and it would be expected that students are affected in the same way. To minimise these effects improved knowledge of HIV nature, impact on both body and health systems and counselling should be provided.

Actual gaps perceived in HIV curriculum content, discussed under principle one (Myezwa 2009), and principle three all contribute to both internal and external domain impacts. Structural issues such as problems experienced around disclosure of HIV status and increased work load have a negative impact on staff, both personally and professionally, for example, (Ukwakwe, 2000).

\section{Principle 5: Importance of developing strategic partnerships}

The range and complexity of problems found when patients were assessed using the ICF checklist show that, in order to be effective in managing HIV patients therapists need to work with other sectors such as social services, to enhance their rehabilitation outcomes and quality of life (Myezwa 2009). In addition disparities evident in the physiotherapy HIV curricula content, demonstrate the need for promoting partnerships between universities in order to maximize on expertise and experience. Strategic partnerships that ensure that mainstreaming and integration of HIV is done efficiently and with some level of quality assurance will also require coorporation at the level of the regulatory and supportive bodies such as other universities, the Health Professions Council of South Africa (HPCSA) and the South African Society of Physiotherapy (SASP). The internal and external domain problems point to the need to also strengthen the collaboration between hospitals and other health care delivery institutions. Doing so will help to define the problem of HIV better and to respond through evidence based and expertise informed knowledge, practice and experience (Canadian Working Group on HIV and rehabilitation, 2002a). The Canadians recognised that this type of strategic partnership is required and they have formed partnerships to bring expertise together across sectors and within rehabilitation programmes.

\section{CONCLUSION}

Identifying entry points and applying mainstreaming principles one reveals challenging points of entry in both education and practice. The range of options indicates the opportunity for introducing a topic so varied and changing as HIV/ AIDS. It raises the need to be abreast with current evidence and to create an environment where inclusion of HIV/ AIDS becomes a real possibility. A number of areas, such as the different body systems, pain, function, activity limitation, the effect of the environment and social determinants where physiotherapists already work, have been pointed out as suitable entry points for introducing HIV/AIDS information. Ensuring that HIV content is incorporated in these areas would successfully fulfil the application of the first mainstreaming principle. The level of detail and the process of learning should be determined by the educators themselves. Unless educators embrace the new content required and successfully integrate it into curricula, the mainstreaming of HIV will remain ineffective and fragmented. Any clinician or academic using these mainstreaming principles can examine their input and identify where HIV has an impact. The ICF is a tool to use in framing the content in each area of teaching. For inclusion in the curriculum, academics and practitioners, perhaps through the use of continuous professional development, need to be sensitised to what is involved and need to be trained in areas where gaps in knowledge, practice and inappropriate attitudes exist. To ensure HIV is mainstreamed into curricula and practice, partnerships between universities, practice areas such as hospitals and communities, patient organisations and regulatory bodies, should be developed.

\section{REFERENCES}

Anandan N, Braveman B, Kielhofner G, Forsyth K. 2006. Impairments and perceived competence in persons living with HIV/AIDS. Work: A Journal of Prevention, Assessment and Rehabilitation 27:255-66

Azzam R, Kedzierska K, Leeansyah E, Chan H, DoischerD, Gorry PR, CunninghamAL, CroweSM, Jaworowski A 2006 Impaired complement mediated phagocytosis by HIV type 1 infected human monocyte derived macrophages involves camp dependent mechanism. AIDS Research and Human Retroviruses 22:619-29

Canadian Working Group on HIV and rehabilitation. 2002a Canadian Working Group on HIV and Rehabilitation. http://www.hivandrehab.ca/ EN/index.php 
Canadian Working Group on HIV and Rehabilitation 2002b Policy Issues on Rehabilitation in the Context of HIV Disease. A background and position paper. http://www.hivandrehab.ca/EN/index.php

Cherner M, Masliah E, Ellis RJ, Marcotte TD, Moore DJ 2002 Neurocognitive dysfunction predicts postmortem findings of HIV encephalitis. Neurology 59:1563-7

CSP. 2008b. CSP Physiotherapy Curriculum Framework Website for Curriculum Framework http://www.csp.org.uk/director/libraryandpublications.cfm

Department of Education. 1999. Department of Education Response to HIV/AIDS.

http://wced.wcape.gov.za/planning\&devel/support/special_ed/hiv_aids/National_policy_on_ HIV-AIDS.pd accessed October 2009

Department of Health. 2007b. HIV/AIDS and STI national strategic plan for South Africa 2007-2011: HIV, AIDS and disability in South Africa South African National AIDS council 2008, Johannesburg

Diaz PT, King MA, Pacht ER, Wewers MD, Gadek JE 1999 The pathophysiology of pulmonary diffusion impairment in Human Immunodeficiency Virus infection. American Journal of Respiratory Critical Care Medicine 160:272-7

Eisner, E. W. (1992). Curriculum ideologies. In The educational imagination (3rd ed., pp. 47-107): Macmillan

Evans RH, Scadden DT 2000 Haematological aspects of HIV infection. Best Practice and Research Clinical Haematology 13:215-30

Flaskrud JH, Ungvarski P 1999 Overview and Update of HIV Disease, HIV/AIDS a Guide to Primary Care Management: J.H. Saunders. pp1-21

Fulk LJ, Kane BE, Phillips KD, Bopp CM, Hand GA. 2004 Depression in HIV-infected patients: Allopathic, complementary, and alternative treatments. Journal of Psychosomatic Research 57:339-51

Galantino MLA, Eke-Okoro ST, Findley TW, Condoluci D 1999 Use of noninvasive electroacupuncture for the treatment of HIV-related peripheral neuropathy: A pilot study. Journal of Alternative and Complementary Medicine 5:135-42

Helander E. 1994. Prejudice and dignity. An introduction to Community Based Rehabilitation UNDP series.

Hunt A, Adamson B, Higgs J, Harris L 1998 University education and the physiotherapy professional. Physiotherapy 84:264-73

Hwang J, Nochajski S 2003 The International Classification of Function, Disability and Health (ICF) and its application with AIDS. Journal of Rehabilitation 69:4-14
Jacobs K, Jacobs L. 2004. Quick Reference Dictionary for OT. Massechusettes USA: Slack incorporated

Kent A, Myer L, Flisher AJ, Mathews C, Lombard C 2005 Introducing HIV/AIDS to South African health sciences students. Medical Teacher 27:647-9

Mutimura E, Stewart A, Rheeder P, Crowther NJ 2007. Metabolic function and the prevalence of lipodystrophy in a population of HIV-infected African subjects receiving highly active Antiretroviral therapy. Journal of Acquired Immune Deficiency Syndrome. 46:451-5

Myezwa H, M'kumbuzi V. 2003. Participation in Community Based Rehabilitation programmes in Zimbabwe: Where are we. Asia Pacific Disability Rehabilitation Journal 14:18-29

Mars M 2004 HIV - implications for exercise in treatment and rehabilitation. South African Journal of Physiotherapy 60:9-17

Mutimura E, Crowther NJ, Cade TW, Yarasheski KE, Stewart A 2008a Exercise training reduces central adiposity and improves metabolic indices in HAART-treated HIV-positive subjects in Rwanda: A randomized controlled trial. AIDS Research Human Retroviruses 24:15-23

exercise training on quality of life in HAARTtreated HIV-positive Rwandan subjects with body fat redistribution. Quality of Life Research 17:377-85

Myezwa H, Stewart A, Solomon P, in press Topics On HIV/AIDS for inclusion into a physical therapy curriculum; consensus through a modified Delphi technique. Journal of physical Therapy Education

Myezwa H, Buchalla, CM Jelsma J, Stewart A, 2011, A HIV/AIDS: use of the ICF in Brazil and South Africa - comparative data from four crosssectional studies Physiotherapy 97: 17-25

Myezwa H, 2008 Mainstreaming HIV into physiotherapy curriculum and practice. $\mathrm{PhD}$ thesis. University of the Witwatersrand

Myezwa H, Stewart A, Musenge E Nesara P 2009 Assessment of HIV-positive in-patients using the International Classification of Functioning, Disability and Health (ICF), at Chris Hani Baragwanath Hospital, Johannesburg. African Journal of AIDS research

Myezwa H, Stewart A, Mbambo N, Nesara P 2005 Status of referral to physiotherapy among HIV positive patients at Chris Hani Baragwanath Hospital Johannesburg South Africa The South African Journal of Physiotherapy: 63 (2) 27-31

\section{Nixon 2010}

Nixon S, O’Brien K, Glazier R, Tynan A 2005 Aerobic exercise interventions for adults living with HIV/AIDS. Cochrane Database Systematic Review 2
O’Brien K, Davis A, Strike C, Young N, Bayoumi A. 2007. Putting disability in to context. Factors that influence the experiences of "disability" for adults living with HIV/AIDS. In WCPT Vancouver Canada

Posner GS, Miguez MJ, Hernandez-Reif M, Perez-Then E 2004 Massage treatment in HIV-1 infected Dominican children: A preliminary report on the efficacy of massage therapy to preserve the immune system in children without antiretroviral medication. The Journal of Alternative and Complementary Medicine 10:1093-5

Puckree T, Chetty BJ, Govender V, Ramparsad S, Lin J 2004 Are physiotherapy graduates adequately prepared to manage HIV/AIDS patients. South African Journal of Physiotherapy 60:7 - 10

Puckree T, Kasiram R, Moodley M, Singh RM, Lin J 2002 Physiotherapists and Human Immunodeficiency Virus / Acquired Immune Deficiency Syndrome: Knowledge and prevention: A study in Durban, South Africa. International Journal of Rehabilitation Research 25:231-4

Ricardo- Dukelow M, Kadiu I, Rozek W, Schlautman J, Persidsky Y Ciborowski P, Kanmogne D Gendelman H 2007 HIV-1 infected monocyte-derived macrophages affect the human brain micro-vascular endothelial cell proteome: New insights into blood-brain barrier dysfunction for HIV-1-associated dementia Journal of Neuroimmulnology 185:37-46

Rusch M, Nixon S, Schilder A, Braitstein P, Chan K, Hogg R 2004 Impairments, activity limitations and participation restrictions: Prevalence and associations among persons living with HIV/ AIDS in British Columbia. Health and Quality of Life Outcomes 2:46

Sattler FR, Jaque SV, Schroeder ET, Olson C, Dube MP, Martinez C, Briggs W, Horton R, Azen S 1999 Effects of pharmacological doses of Nandrolone Decanoate and progressive resistance training in immunodeficient patients infected with Human Immunodeficiency Virus. The Journal of ClinicalEndocrinology and Metabolism84:1268-76

Sattler FR, Schroeder ET, Dube MP, Jaque SV, Martinez C, Blanche PJ, Azen S, Krauss RM 2002 Metabolic effects of Nandrolone Decanoate and resistance training in men with HIV. American Journal of Physiology Endocrinology Metabolism 283:1214-22

Solomon P, Salvatori P, Guenter D. 2003b. Interprofessional professional problem-based learning course on rehabilitation issues in HIV. Medical Teacher 25:408-13

Shor-Posner G, Miguez M-J, Hernandez-Reif M, Perez-Then E, Fletcher M 2004 Massage treatment in HIV-1 infected Dominican children: A preliminary report on the efficacy of massage therapy to preserve the immune system in children without Antiretroviral medication: 1093-5 
Ukwakwe CBU 2000 Systemised HIV/AIDS education for student nurses at the University of Ibadan, Nigeria: Impact on knowledge, attitudes and compliance with universal precautions. Journal of Advanced Nursing 32:416-24

Uwimana J, Louw Q. 2007. Effectiveness of palliative care including physiotherapy in HIV patients a literature review South African Journal of Physiotherapy 63:41 - 6

UNAIDS. 2002. UNAIDS mainstreaming HIV/AIDS: A Conceptual Framework and ImplementingPrinciples.Accra http://www.unaidsrstesa.org/Documents/thematic_areas/mainstreaming.html accessed April 2009

Verbrugenn B 2004 Mainstreaming HIV AIDS. Organisation Paper Frankfurt: GTZ/UNAID

Van As M, Myezwa H, Stewart A, Maleka D, Musenge E 2009 The international classification of function (ICF) in adults visiting the HIV outpatient clinic at a regional hospital in Johannesburg, South Africa. Aids Care 21:1 50-58
Vance R, Denham S. 2008. HIV/AIDS related stigma: Delivering appropriate nursing care. Teaching and Learning in Nursing 3:59-66

Vidrine DJ, Amick BC, Gritz ER, Arduino RC. 2003. Functional status and overall Quality of Life in a multiethnic HIV-positive population. AIDS Patient Care and STDs 17:187-97

Volberding PA, Baker KR, Levine AM. 2003. Human Immunodeficiency Virus. Hematology 2003:294-313

Worthington C, Myers T, O'Brien K, Nixon S, Cockerill R 2005 Rehabilitation in HIV/AIDS: Development of an expanded conceptual framework. AIDS Patient Care \& STDs 19:258-71

Zinna E, Yarasheski KE 2003 Exercise treatment to counter act protein wasting of chronic diseases Current Opinion in Clinical Nutrition and Metabolic Care 6:87-93

Zonta MB, de Almeida SM, de Carvalho TM, Werneck LC 2003 Functional assessment of patients with AIDS disease. The Brazilian Journal of Infectious Diseases 7:301 - 6

Zonta MB, de Almeida SM, de Carvalho TM, Werneck LC 2005 Evaluation of AIDS-related disability in a general hospital in Southern Brazil. The Brazilian Journal of Infectious Diseases 9:479-88

\section{AccountsdotCom offers!}

o

$\circ$

○

$\circ$

o

○

o

○

0

o

○

o

$\circ$

o

charging to be hand collected, e-mailed or faxed

billing and submitting via QEDI

sending statements to patients via post, fax or e-mail

sending weekly sms messages for member liable accounts

taking legal steps for bad debt, without extra costs

reconciliation with medical aid on accounts from 60 days

full reconciliation report

banking of cheques for the practice

printing of all month end documents

printing of locum reports for easy payments

hand delivering of all IOD / Polmed IOD accounts

handling of all public inquiries

reconciliation of medical payments with practitioners bank statements

handling of all extra requests

\section{All this for a set fee!}

If you're looking for extra special service where the practitioner as well as the patient's needs are handled with the utmost care ... AccountsdotCom is the solution!

Phone now 012 653-7200 or 012 653-7122 or fax 012 653-7850 or

e-mail accountsdotcom@gmail.com 